\title{
The Effect of Landscape Architecture on Climate Change
}

\author{
Nazanin Nafici, M. F. M. Zain \\ Department of Architecture, Universiti Kebangsaan Malaysia \\ 43600, Bangi, Selangor, Malaysia \\ E-mail:n.nazanin68@gmail.com,fauzizain@gmail.com
}

\begin{abstract}
Permanent environmental influences such as sun, fog, acid rain can destroy structures, buildings and the environment. Improving the quality of urban environment with utilizing green roof and green facades is illustrated for several years and installing them can offer multiple benefits. A detailed integrated presentation of green roof and green facade systems is provided in this paper. The aim of the research is to illustrate the effect of green façade and green roofs and generally greenery structure on the climate changes. The author tries to find a solution for the climate changes and environmental issues and resolving it by above- mentioned landscape architecture methods.
\end{abstract}

Keywords — climate change; green roof; green façade; landscape

\section{INTRODUCTION}

Urban areas have a great role in the climate change. Attention to the climate changes represents our best chance to improve quality of life for the greatest number of people across the world. As a matter of fact, attention to the urban areas and its climate problems, like pollution can be a key factor solution of climate changes. Several features of modern cities interact with the changing climate to exacerbate the risks and increase vulnerability to climate change.

Plants absorb sunlight to photosynthesize and grow, and their colouring reflects infrared. Because lush vegetation rarely exists as part of the urban landscape, save a few shrubs and some grass or potted plants, there is very little protecting a city from increased temperatures. Reflectivity aside, plants also contribute to moisture in the air which produces a cooling effect. Cities are where individuals may be the most vulnerable to the health implications of climate change. Important features for urban environment in landscape architecture that can be used in the productive way are building facades. Current-day green facades offer the potential to learn from traditional architecture but also to incorporate advance materials and other technology to promote sustainable building functions.

Using green facades and green roof for building entrance, healing garden could take advantage of improvement to the human which can be provided by plants and this means improving of the quality of human experience in built environment. It is very important to choose plant species carefully that can it thrive under project site conditions. For example, under colder climates condition there are species of vines that even during the winter months they maintain their foliage. In design step of the projects in temperate climate zones, changing of seasons and how different plants will display their adaption to the environment should be considered. The aesthetic of green wall can be dramatically affected by these environmentally changes.

\section{GREEN RoOF}

A green roof is a roof of a building that is partially or completely covered with vegetation and a growing medium, planted over a waterproofing membrane. It may also include additional layers such as a root barrier and drainage and irrigation systems. [1] There are two kinds of green roofs such as intensive and extensive. Extensive green roofs: growing medium is from 50 to $200 \mathrm{~mm}$ and vegetation limited to shallow rooting plants.

Intensive Green Roofs: Deep growing medium that is about $200 \mathrm{~mm}$ or greater. It requires stronger roof structure, Wide range of planting possible,

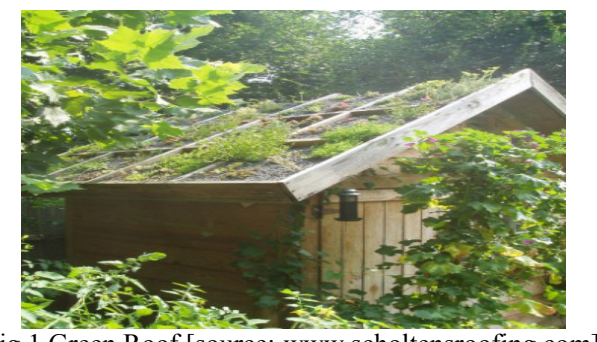

Fig.1 Green Roof [source: www.scholtensroofing.com] 


\section{PLANTS}

Studying on plants for landscape design and architecture is an important research area [2], and recently, researches are written on plants of green roof structure. However it should be noted that plant selection is related to the region which the project is implementing.

Weather, humidity and geographical location of structure and building play an important role in defining plant types [3]. Structural loading limitations, climate, irrigation, heat tolerant and depth of growth media can effect on selection of plants. Some kind of plants such as Sedums, other succulents, and ground covers can have no problem with little water and endure high heat.

In contrast, plants like wetland plants, prairie plants and native grasses to need aggressive irrigation regimes. They need continues maintenance. Roof membrane should be kept damages that come by root of plants; this will be solved by a good root barrier.

\section{IV.Seeds, Cutting, or Plugs and Drought Tolerance}

Germinating plants on green roof can be done by seeds, but it needs a lot of irrigation. If it is a large project, that's need of installing the commercial type irrigation system for wetting the surface constantly. Seeds are small and plant distribution, and design is difficult. (a)

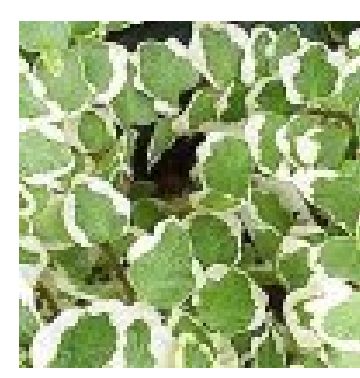

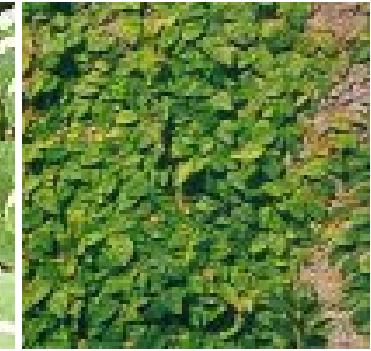

(b)
Fig.2 Climbing plants [source: http://greenhaus.co.nz/climbers.html]

Cuttings or cloning is done to matured plants and putting it in soil to make new plants. It also needs irrigation but it is less expensive than seed method and after one or two season, the full coverage of plants will be on the roof.

Plugs which are mostly used in green roof projects are young plants with semi grown root. Plugs will develop in six to eight weeks in greenhouses. Their viability is very good rather than seeds and cutting. Since plugs can be used as a divider, they are suitable for designing the appearance. In some cases, the combination of cutting and plug is visible in the projects.

Drought and heat are related to each other and plant's ability to resist without hydration is drought tolerance, and it varies plant to plant. It is important to know that using plants to withstand fully with heat is not a good idea; in contrast, using them with a good irrigation system is a good choice.

\section{GREEN FACADE}

Important features for urban environment in architecture that can be used in the productive way are building facades. Current-day green facades offer the potential to learn from traditional architecture. It also incorporates advance materials and other technology to promote sustainable building functions [4].

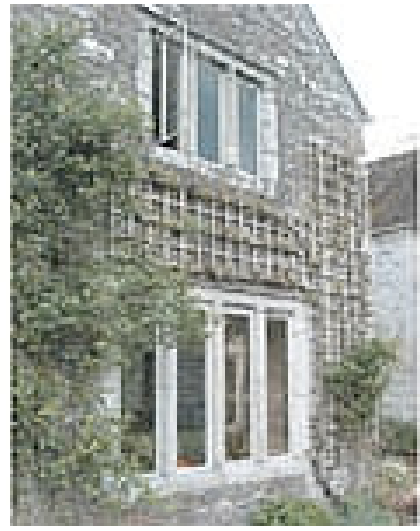

Fig.3 Green Facade [source: www.architectureweek.com]

Green façades are made up of climbing plants either growing directly on a wall or, more recently, specially designed supporting structures. The plant shoot system grows up the side of the building while being rooted in the ground. With a living wall, the modular panels are often made of stainless steel containers, geotextiles, irrigation systems, a growing medium and vegetation. [5]

\section{AESTHESTICS}

Main design objective of most green façade projects is improving the aesthetic view. There are so many places, which can be used for green facade to improve their aesthetic such as campus buildings, large parking structures and even condominiums. Designing facades with utilizing plant textures, rhythm and shapes and patterns can distribute aesthetic improvement. Green façades can be used to isolate view and screen and hiding equipment, service area or other aspect of building system requirement that effect aesthetic aspect. As an aesthetic improvement can be used as interior applications and normally in this case is called Green Wall. For improving the aesthetic aspect the plant material can be flowering. This may cause change by every season or change their visual character significantly. It is a small footprint, and naturally, they are in vertical shape. These are reasons to create large and efficient green areas. Aesthetic level and value are not related to quantitative evaluation of materials and performance of the system but it is related to interaction of human.

\section{ENVIRONMENT PROBLEM CLIMATE CHANGE (GLOBAL WARMING)}

Changing in the average of weather or distribution of weather in the earth is called climate change. Global warming is a result of increasing in average temperature of 
the earth. It is expected that during the 21 st century, temperature of global surface is raising a further 1.1 to $6.4{ }^{\circ} \mathrm{C}$. Different factors can have effect on climate change such as earth's orbit, solar radiation, green house gas concentration, human activities and, etc. In the following two of them that are related to this research are described in more detail.

\section{ADVANTAGE OF GREEN ROOF AND GREEN FACADE}

Aesthetic view of green projects is the first advantage which people sense and enjoy. This benefit will cause to bring calm to the cities. It can affect directly the behavior and activities of people around the implemented green projects. It can be non economical incentives that can encourage people to invest their money in these environmental friendly projects.

\section{SOUND AND NOISE INSUlATION}

Because of different layers of materials that are used in the green projects, they can absorb sound waves and prevent them to enter the buildings. But it should be noted that intensive green roof projects have higher effect than extensive ones. Van Renterghem \& Botteldooren, [6] mentioned that covered roofs have a linear relationship with decreasing sound pressure level. Van Renterghem and Botteldooren studied numerical evaluation of propagated sounds over green roofs and façades. Although the presence of plants was not considered in that research, but it shows that extensive and intensive green roofs reduce the diffracting waves over the building and higher layer thickness of green roofs have higher attenuation.

In another research in 2009, Van Renterghem and Botteldooren studied reduction of sound and noise which is produced by a single line, light traffic at a constant speed in presence of green roof and facade. He concludes that noise reduction effect increases with high speed light vehicles. In case of heavy ones this effect is still noticeable but not increases [7].

\section{Air POLLUTION}

Air pollution is a major threat to human health [8]. The United Nations Population Fund [9] predicted that the urban population worldwide would increase from 3.3 billion in 2008 to 5 billion by 2030 . Air pollutant removal by green roofs has been studied in different areas, for example, Currie and Bass [10] in Toronto estimate that 7.8 tons of air pollutant will remove by 109 ha of green area, but Yang and $\mathrm{Yu}$ in their study in Chicago showed that by using 19.8 ha of green surfaces $1675 \mathrm{~kg}$ of air pollutants was removed in one year, They also mentioned the percentage of removed pollutants as follow: $\mathrm{O}^{3}(52 \%), \mathrm{NO}^{2}(27 \%), \mathrm{PM} 10$ (14\%) and $\mathrm{SO}^{2}(7 \%)$.

\section{CONCLUSION}

The most notable advantage of using a green roof and green facade construction is modifying of temperature.

Climate is changing, due to the increasing of human produced carbon pollution. These changes enhance the global average air and ocean temperature, widespread melting of snow and ice and rising global sea levels and extra heat in the climate system have other impacts, of climate change.

The green infrastructure offer many benefits to an urban area and existing environment, benefit to both micro climates of indoor environment and surrounding outdoor environment of the building. It contributes to reducing energy consumption for cooling load, also reduces the effect of global warming by controlling the $\mathrm{CO} 2$ level.

In summary, other impressions of the green infrastructure are: Improving water quality, reduce urban heat-island effects, cleaning the air, Reducing sound reflection and transmission, creating wildlife habitat, and finally, psychologist claims looking at plants and trees "will benefit you enormously" and stressed can reduce mental and physical strain by up to $60 \%$ by staring at greenery for 15 minutes.

\section{REFRENCES}

[1] http://en.wikipedia.org/wiki/Green roof

[2] Simonds, J.O. 1998. Landscape architecture: a manual of site planning and design, New York: McGraw-Hill Professiona

[3] Snodgrass, E.C. \& Snodgrass, L.I. 2006. Green roof plants a resource and planting guide. Portland, Or. London: Timber.

[4] Köhler, M. 2008. Green facades-a view back and some visions. Urban Ecosystems 11 (4): 423-436.

[5] http://en.wikipedia.org/wiki/Green_wall

[6] Van Renterghem, T. \& Botteldooren, D. 2008. Numerical evaluation of sound propagating over green roofs. Journal of Sound and Vibration 317 (3-5): 781-799.

[7] Van Renterghem, T. \& Botteldooren, D. 2009. Reducing the acoustical façade load from road traffic with green roofs. Building and Environment 44 (5): 1081-1087.

[8] Yang, J. \& Yu, Q. 2008. Quantifying air pollution removal by green roofs in Chicago. Atmospheric Environment 42 (31): 7266-7273.

[9] UNFPA. 2007. State of world population 2007 unleashing the potential of urban growth, UNFPA.

[10] Currie, B.A. \& Bass, B. 2008. Estimates of air pollution mitigation with green plants and green roofs using the UFORE model. Urban Ecosystems 11 (4): 409-422.

[11] http://www.scholtensroofing.com/Rooftypes-Vancouver/GreenRoofing-Vancouver.html

[12] http://www.architectureweek.com/2004/0728/environment_1-2.html

[13] http://greenhaus.co.nz/climbers.html 